\title{
Editorial
}

\section{Acute Poisoning - A Neglected Topic}

\section{Dr. Mohammad Rafiqul Islam ${ }^{1}$}

Acute poisoning is a common medical emergency in Bangladesh. It is the $7^{\text {th }}$ commonest cause of in hospital mortality in Bangladesh. ${ }^{1}$ Huge burden of poisoning requires comprehensive intervention strategies and effective management to reduce case burden and mortality. Unfortunately, in Bangladesh, there is no poisoning center to provide information regarding poisoning and its management protocol. According to WHO 99\% fatal poisoning cases are from developing country ${ }^{2}$. Deliberate self-poisoning is increasing significantly in developing country where drugs are dispensed without prescription and pesticides are sold without proper license and monitoring. In a survey done in primary (sub-district), secondary (district) and tertiary (medical college) level hospitals in Bangladesh, the case load of poisoning was totally found to be $14.5 \%$ admitted patients ${ }^{3}$. Bangladesh is an agro based country and use of pesticide is common to increase food production. Major classes of pesticides are insecticide, fungicide, rodenticide, herbicide. Insecticide and fungicide accounts $97 \%$ of pesticide use in Bangladesh. Chemical analysis reveals Carbamates and OPCs used insecticides and dithiocarbamates used in fungicides. Major classes of pesticide used by Bangladeshi farmers are cypermethrin, dichlorvos, malathion, carbofuran, mancozeb and diazinon. In the urban setting, components of acute poisoning are little different. Benzodiazepines, amitritptyline, paracetamol, Harpic (10\% Hydrochloric acid), copper sulphate and multiple drug combinations are used for poisoning. Aluminum phosphide poisoning and snake bite are also major concern in acute poisoning.

Good history taking, toxidorm analysis and sample identification can increase the survival rate in acute poisoning management. Most poisoned patient can be managed by supportive care only. Challenging part of management is identification of patients who are at risk developing serious clinical toxicity and who will benefit from supportive care and specific intervention. During supportive care airway, breathing and circulation management especially skill on endotracheal intubation plays a tremendous role in poisoning patient management. Gut decontamination, appropriate antidote uses and toxin elimination remains as cornerstone in acute poisoning case management. In OPC poisoning, doubling atropine dose during acute management reduces time of atropinization. In corrosive poisoning, upper gastro intestinal endoscopy within 24 hours can predict management protocol according to Zagar's modified endoscopic classification. Deliberate self-poisoning patients require

${ }^{1}$ Dr. Mohammad Rafiqul Islam, Associate Professor of Medicine, Shaheed M Monsur Ali Medical College, Sirajganj. 
TAJ June 2017; Volume 30 Number-1 $\begin{aligned} & \text { psychological treatment after acute } \\ & \text { management. }\end{aligned}$
Community Health 2012;24:248-51.

3. Faiz MA ,Swapon MR, Basher A, Ghose A,

\section{References:}

1. Directorate General of Health Services (DGHS), Bangladesh. Health Bulletin 2012. Dhaka: DGHS; 2012.

2. Kumar A, Verma A, Jaiswal K, Kumar S, Prasad R. Emergence of entirely new Amin R. Baseline survey on cases of Poisoning and its Outcome in Bangladesh. Abstract presented at the 6th APAMT Congress; 2007 Dec 12-14; Bangkok, Thailand. poisoning in rural India; An upcoming health

All correspondence toDr. Mohammad Rafiqul Islam Associate Professor of Medicine Shaheed M Monsur Ali Medical College, Sirajganj. Email: drrafiq73@yahoo.com 